arterial blood gas measurements are required in the first 6-8 hours to allow the physician to judge the efficacy of NIV and the need for invasive ventilation.

A Agarwal R, Reddy C, Gupta D. Nonivasive ventilation in acute neuromuscular respiratory failure due to nyasthenic crisis: case report and review of literature. Emerg Med J 2006;23:e6. http://emjonline.com/cgi/content/full/23/1/e6. doi 10.1136/emi.2004.019190

\section{Hypopharyngeal perforation following minor trauma: a case report and literature} review A rare complication of non-penetrating blunt neck trauma, hypopharyngeal perforation is mainly reported in association with high velocity road traffic accidents. The proposed injury mechanism is neck hyperextension associated with airway closure due to cervical compression against the steering wheel. Low velocity direct blows to the neck have also been associated with pharyngeal perforation. We report a case of hypopharyngeal perforation following a low velocity motorcycle accident where neither mechanism of injury was apparent. The presumed mechanism of injury in this case was cervical spine hyperextension without cervical compression.

\ Smith D, Woolley S. Hypopharyngeal perforation following minor trauma: a case report and literature review. Emerg Med J 2006;23:e7. http://emjonline. com/cgi/content/full/23/1/e7. doi: 10.1136/emj.2003.012187
Two cases of retroperitoneal haematoma caused by interaction between antibiotics and warfarin A number of commonly prescribed antibiotics are known to interact with warfarin, increasing its anticoagulant effect by different mechanisms. Retroperitoneal bleeding and consequent haematoma is well recognised as a complication of over-anticoagulation. Consequences, which are potentially fatal, include hypovolaemic shock and compression of retroperitoneal structures such as the ureter and inferior vena cava (IVC). We present two such cases and a discussion of the issues, which are raised. The first patient was being anticoagulated as treatment for pulmonary embolus. Antibiotics including trimethoprim and metronidazole were used to treat a urinary tract infection. The second patient was prescribed warfarin after suffering transient ischaemic attacks and being diagnosed with paroxysmal atrial fibrillation. A lower respiratory tract infection was treated with a macrolide antibiotic. In both cases the effect of warfarin was potentiated and the patients suffered bleeding complications.

\ Phillips A, Barr A, Wilson E, et al. Two cases of retroperitoneal haematoma caused by interaction between antibiotics and warfarin. Emerg Med J 2006; 23:e8. http://emjonline.com/cgi/content/full/23/1/e8. doi: 10.1136/ emi.2004.016345

\title{
Images in Emergency Medicine: Acute severe coronary spasm associated with 5-fluorouracil chemotherapy
}

C ardiotoxicity is an uncommon adverse effect of 5-FU treatment. Prevalence of 5- fluorouracil (FU) - induced clinical challenge. ${ }^{1}$ A 62 year old male was admitted to our emergency department with severe dyspnea, chest pain, diaphoresis, nausea, and pruritis after the completition of a regimen of 5-FU chemotherapy for gastric adenocarcinoma. The ECG showed sinus tachycardia and global ST segment

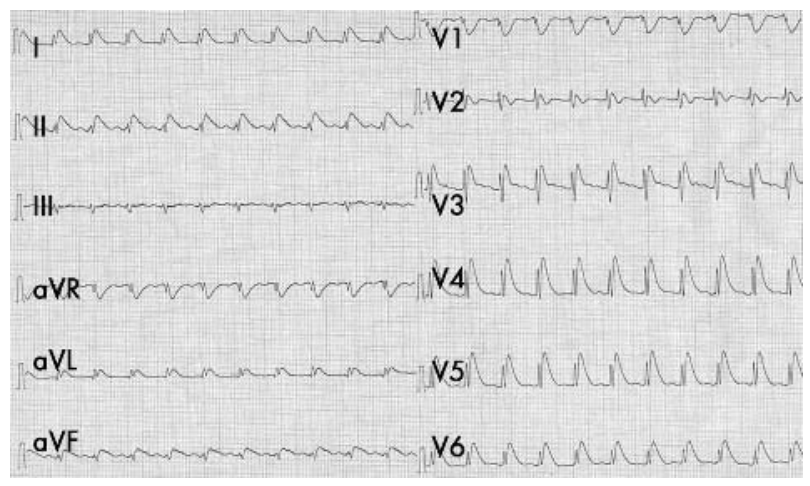

Figure 1 ECG shows severe and extensive ST segment elevations early after the treatment. elevation in all leads except in DIII, aVR and Vl (Fig 1). Chest pain and ECG changes resolved at $30^{\text {th }}$ minute of the nitroglycerin infusion with the dose of $60 \mu \mathrm{g}$ per minute. Coronary angiography has not demonstrated any pathology.

The patient was discharged on medical therapy including ASA, amlodipine $5 \mathrm{mg}$, atorvastatin $10 \mathrm{mg}$. He has been symptom-free for six months.

S Duran, S Bulur, S Bahadir Sozen, Abant lizzet Baysal University Düzce Faculty of Medicine, Department of Cardiology 81620, Konuralp Düzce, TURKEY

C Bilir, Abant izzet Baysal University Düzce Faculty of Medicine Department of Internal Medicine 81620, Konuralp Düzce TURKEY

C Uyan, Abant Izzet Baysal University, Izzet Baysal Medical School, Department
of Cardiology, 14000 Bolu, TURKEY

R Akdemir,

Abant Izzet Baysal University Düzce Faculty of Medicine, Department of Cardiology 81620, Konuralp Düzce, TURKEY Correspondence to: Ramazan Akdemir, MD, Abant İzzet Baysal Universitesi, Düzce Tıp Fakültesi 81620, Konuralp Düzce TURKEY; rakdemir@yahoo.com

\section{REFERENCES}

1 Luwaert RJ, Descamps $O$, Majois F, et al. Coronary artery spasm induced by 5-fluorouracil. Eur Heart J 1991;12:468-70. 